\title{
Neonatal Outcomes Among Survivors of Twin-twin Transfusion Syndrome After Single Fetal Demise
}

\author{
Ya-Lan Lin \\ Cathay General Hospital \\ Yi-Li Hung \\ Cathay General Hospital \\ Chung-Min Shen \\ Cathay General Hospital \\ Wu-Shiun Hsieh ( $\square$ hsiehws@ntu.edu.tw) \\ Cathay General Hospital https://orcid.org/0000-0002-0609-3311
}

Research article

Keywords: twin-twin transfusion syndrome, single-twin intrauterine demise, mortality, morbidity

Posted Date: November 23rd, 2020

DOI: https://doi.org/10.21203/rs.3.rs-106963/v1

License: (c) (i) This work is licensed under a Creative Commons Attribution 4.0 International License. Read Full License 


\section{Abstract}

Twin-twin transfusion syndrome (TTTS) is due to unbalanced inter-twin blood flow. We aimed to evaluate neonatal outcomes among surviving co-twins of TTTS without fetal laser photocoagulation after single-twin intrauterine fetal demise (sIUFD). All patients admitted between January 2014 and December 2017 to the neonatal intensive care unit of a medical center were recruited. Moreover, a comprehensive literature review of PubMed from 1993 to 2020 was performed. Medical records of 124 patients were retrieved, including 119 from published literature and five from our institution. Seventy-three (58.8\%) patients were born prematurely. In addition, twenty-four (19.3\%) patients presented with anemia at birth, and seventeen (13.7\%), four (3.2\%), and four (3.2\%) neonates had intracranial lesions, acute kidney injury, and gastrointestinal (GI) tract dysmotility, respectively. The overall survival rate was $69.4 \%$. Among our cases, we found that the hemoglobin level at birth was positively correlated with the duration between co-twin intrauterine fetal demise and the delivery time of the surviving co-twins $\left(r_{s}=0.9, p=0.037\right)$.

Conclusions. High morbidity and mortality rates were observed among co-twins of TTTS after sIUFD without laser photocoagulation. The shorter duration between diagnosis of sIUFD and surviving twin delivery resulted in more severe anemia.

\section{Introduction}

Twin pregnancies carry higher perinatal mortality and morbidity rates than singleton pregnancies [1]. Unbalanced inter-twin blood flow may cause twin-twin transfusion syndrome (TTTS) or twin anemia-polycythemia sequence during pregnancy. However, sIUFD may occur. Although previous studies have reported that TTTS survivors had worse neurodevelopmental outcomes [2,3], less discussion has been available regarding other morbidity of survivors after sIUFD. Moore et al. hypothesized that the release of thromboplastic and necrotic emboli from the demised twin could cause damage to several organs in the surviving twins [4]. Moreover, Fusi et al. hypothesized that cranial lesions observed in the surviving twins were often due to ischemia-related damage occurring before intrauterine demise, for which early intervention before the occurrence of SIUFD was recommended to prevent subsequent neurological sequelae [5]. However, not every patient has the opportunity to undergo laser photocoagulation. Accordingly, the present study aimed to evaluate the neonatal outcomes among co-twins of TTTS who survived sIUFD without laser photocoagulation.

\section{Materials And Methods}

This retrospective study included patients who survived TTTS after sIUFD from January 2014 to December 2017 in our neonatal intensive care unit. TTTS was diagnosed based on the following criteria: (1) a monochorionic diamniotic pregnancy and (2) oligohydramnios (defined as a maximal vertical pocket of $<2 \mathrm{~cm}$ ) in one sac and polyhydramnios (a maximal vertical pocket of $>8 \mathrm{~cm}$ ) in the other sac within the first 20 weeks of gestation or $\geq 10 \mathrm{~cm}$ after 20 weeks of gestation [6]. A retrospective chart review was performed to collect data on neonatal morbidities, including anemia severity, thrombocytopenia and disseminated intravascular coagulation (DIC) occurrence, intracranial hemorrhagic infarction incidence, encephalomalacia, renal damage, non-anatomically obstructive GI dysmotility, and death. GI dysmotility was defined as receiving less than half of the total daily fluid intake or less than $75 \mathrm{~mL} / \mathrm{kg} /$ day of milk feeds through the enteral route on day 14 [7]. To supplement our experience, a systemic literature review of PubMed from 1993 to 2020 was performed using the MeSH terms "Twin to twin transfusion syndrome "and "single-twin intrauterine fetal demise." In an attempt to include as many cases as possible, all full-text articles, written in English, including case reports, were retrieved and analyzed. Perinatal characteristics, morbidity, and mortality of the patients were extracted from the selected articles and our patients.

\section{Results}

Five TTTS cases, each with one surviving co-twin after sIUFD, were recruited in our hospital. Gestational ages (GAs) were $29^{2 / 7}, 30^{1 / 7}, 30^{1 / 7}$, $32^{6 / 7}$, and $33^{1 / 7}$ weeks, with sIUFD occurring at $20,25^{4 / 7}, 30,32^{1 / 7}$, and $32^{6 / 7}$ weeks, respectively. The birth weights of the surviving co-twins were $1,247,1,158,1,523,2,361$, and 1,545 g, respectively.

Among the pregnancies, only one had undergone amnioreduction twice at GA 26 and 27 weeks. None of the cases had undergone fetoscopic laser photocoagulation or intrauterine transfusion before labor. Anemia (hemoglobin, 5-11.7 g/dL) was observed in four patients after birth. Only one survivor, who was delivered 58 days after sIUFD at GA 292/7 weeks, had a normal hemoglobin level at birth. We found that a longer duration between sIUFD diagnosis and delivery of the surviving co-twin resulted in higher hemoglobin levels at birth.

There was a positive correlation between the duration of co-twin intrauterine fetal demise and the delivery time of surviving co-twins $\left(r_{s}=0.9, n=5\right.$, $\mathrm{p}=0.037)$.

Four patients had non-anatomically obstructive GI dysmotility presenting with increased gastric residual before feeding and marked abdominal distension with or without dilated intestinal loops. The duration needed to reach full enteral feeding was prolonged (mean: $50.6 \pm 36.8$ days, 
median: 46 days). Three patients displayed renal function impairment, two of whom exhibited stage 2 acute kidney injury [8]. The condition progressed to chronic kidney disease in one of the patients.

Two patients presented with multiple hemorrhagic infarctions diagnosed through cranial ultrasound at day 1 of life. Both were delivered at GA $30^{1 / 7}$ weeks, with sIUFD occurring at $25^{4 / 7}$ and 30 weeks. One of the two patients exhibited periventricular leukomalacia on the same day, and multiple hemorrhagic infarctions were diagnosed. The other patient, who underwent magnetic resonance imaging (MRI) at day 129 , also exhibited multicystic encephalomalacia with bilateral ventriculomegaly. Both patients displayed severe thrombocytopenia with platelet counts of $57 \times 10^{3} / \mu \mathrm{L}$ and $45 \times 10^{3} / \mu \mathrm{L}$. One case was complicated with disseminated intravascular coagulopathy. Compared with the aforementioned three patients, these two patients exhibited more complications, including anemia, acute kidney injury, GI dysmotility, and neurodevelopmental impairment. Ultimately, both of them died, one due to neurological complications and the other due to renal failure. Although the three remaining twins presented with mildly to moderately increased periventricular echogenicity after birth, both were resolved afterwards and no neurodevelopmental impairment was noted at during follow-up.

\section{Review of Literature}

Our literature review identified 11 articles that yielded 124 cases, including five of our cases (Table). Prematurity was reported in 73 (58.8 \%) patients. Only 43 cases had been mentioned for the interval between sIUFD and delivery with a mean of 10.5 (0-58) days. Twenty-four neonates (19.3\%) developed anemia after birth. Nine of these patients had undergone intrauterine blood transfusion. Neurological damage was noted in $17(13.7 \%)$ patients. All patients of neurological damage had cerebral lesions on initial cranial ultrasound, and eight of them had been mentioned as having neurodevelopmental impairment. Only four (3.2\%) patients had been mentioned as having kidney injury (one from published literature, three from our institution). In addition, four patients in our study had GI dysmotility. However, none of the published studies demonstrated the condition of GI dysmotility. The overall neonatal mortality rate was $30.6 \%$.

\section{Discussion}

Several studies have discussed survivors of sIUFD, including all the causes of sIUFD, such as genetic or congenital abnormalities. However, this review focused on the outcomes of survivors after sIUFD, which were due to TTTS.

Over $19.3 \%$ of surviving co-twins developed anemia after birth in this literature review. In fact, the incidence of anemia might be underdiagnosed because intrauterine blood transfusion had been performed, and fetal anemia had been corrected in 19 patients, as reported by Quarello et al. [10]. Profound anemia can cause ischemia of the vital organs, such as the brain, liver, and kidney. In our patients, we found that a shorter interval between sIUFD diagnosis and delivery of the surviving co-twin resulted in lower hemoglobin levels. The only patient with a normal hemoglobin level was born at GA of $29^{2 / 7}$ weeks, but with a long interval of 58 days between slUFD diagnosis and delivery. We hypothesized that the length of the interval between sIUFD diagnosis and delivery might considerably affect the anemia severity, which has not been mentioned in previous studies. Fuisi et al. hypothesized that anemia was due to acute exsanguination of the surviving twin into the low-pressure hemodynamic circulation of the demised co-twin [5], which caused acute blood loss. Senat et al. also noted that cardiac contractility increased after sIUFD. We inferred that anemia might be acute and transient, which could be improved later after a long interval between slUFD and delivery of the surviving co-twin.

Among the cases of the literature review and our cases, 17 (13.7\%) patients of surviving co-twins without fetal laser photocoagulation therapy had developed neurological damage. The incidence of neurological impairment was similar to that reported by Akkermans et al. They showed that the incidence ranged from $8 \%$ to $18 \%$ after laser therapy [9]. Whether fetal laser photocoagulation could alleviate the neurological damage of the surviving co-twin remains uncertain. Two of our patients developed hemorrhagic infarctions soon after birth. One of them developed encephalomalacia within $24 \mathrm{~h}$ after birth, suggesting an antenatal white matter injury. Kiely et al. reported that cerebral abnormalities were usually detectable by prenatal ultrasound or MRI within 3-6 weeks of the death of the co-twin [10]. Furthermore, Eglowstein et al. found that one patient presented with periventricular leukomalacia $24 \mathrm{~h}$ after the demise of the co-twins [11], suggesting that the timing of neurological damage could be early before intrauterine death of the co-twins. Consequently, not only sIUFD could induce neurological damage, but patients with TTTS might be at risk of developing neurological injury.

Considering the progressive fetal brain development, distinct timing of sIUFD might result in various presentations of brain damage. The TTTS phenomenon usually becomes prominent during the second trimester. If sIUFD occurred early in the second trimester, it could cause disturbances in neuronal migration and leads to polymicrogyria [12]. During the third trimester, the brain size linearly increases by four-fold, while cortical folding and wiring begin developing. The brain is thus more vulnerable to cerebral ischemic damage during this period. Two of our patients with poor neurodevelopmental outcomes succumbed to sIUFD at GA $25^{4 / 7}$ and 30 weeks, respectively. The other three survivors who did not develop poor neurodevelopmental outcomes had sIUFD at gestational age less than 20 weeks in one patient and over 32 weeks in the other two patients. Because the brain is undergoing rapid growth and maturation during the late second trimester and early third trimester, we suggest that sIUFD occurring between these periods should raise more concerns about poor neurodevelopmental outcomes.

Page $3 / 6$ 
Four patients had acute kidney injury, including three of our cases. One pathological study revealed that donor twins displayed renal tubular dysgenesis. [14] They hypothesized that TTTS-related hypoperfusion along with hypofiltration deferred proximal tubular development, leading to renal tubular dysgenesis [14]. Although two of our patients recovered from acute kidney damage, one patient progressed to chronic kidney disease. According to a recent study, the incidence of chronic kidney disease among twins with TTTS was high, with approximately $31 \%-50 \%$ of such patients requiring long-term renal replacement therapy [15]. However, this study excluded surviving twins after slUFD. Therefore, further study recruiting surviving twins after sIUFD is warranted.

Only a few articles reported GI dysmotility in TTTS survivors after sIUFD. However, in our study, this was an important issue. The probability of preterm delivery was high among TTTS survivors. Nutrition was the key point for early discharge and prevention of several complications of prematurity. All of our patients demonstrated GI dysmotility. They exhibited GI dysmotility during the first week of life and were capable of full enteral feeding at a median of 46 days, which was longer than the usual clinical course. Robel-Tillig et al. reported that the pathological blood flow parameters in the superior mesenteric artery could predict problems in intestinal motility and tolerance to enteral feeding [16]. Neonates with decreased peak systolic flow velocity and increased superior mesenteric artery pulsatility indexes were at risk for poor enteral feeding after birth. According to the diving reflex theory, antenatal hypoxia may cause blood flow redistribution to the vital organs rather than the intestinal circulation, leading to persistent intestinal vascular bed vasoconstriction [16]. The increased GI blood flow after feeding helps satisfy the oxidative demand for intestinal absorption, which is called postprandial hyperemia [17]. During the neonatal period, pressure-flow autoregulation is insufficient. The high resistance within the intestinal vasculature compromises blood flow throughout the GI tract [12]. We suggest that the failure of vasodilation and upregulation of the intestinal blood flow in TTTS survivors after sIUFD may lead to feeding intolerance and GI dysmotility [17].

Our study documented that the mortality rate of the surviving twins of TTTS after sIUFD was up to $30 \%$, which was much higher than that of the non-TTTS twins with sIUFD. [18.19] The mortality and morbidity rates might be affected by the interval between sIUFD and delivery time. Johsnosn et al. reported that the survival of the remaining fetuses was inversely related to the time of the first fetal demise. [20]. However, this study included all the causes of sIUFD and collected all monochorionic and dichorionic placentation. [20] One study showed that postnatal mortality will increase when sIUFD occurs during the second trimester, a vulnerable period, associated with a high incidence of growth retardation, premature labor, and perinatal mortality [21]. Moreover, both of our two mortality cases suffered from thrombocytopenia soon after birth. One of them had developed DIC within $24 \mathrm{~h}$ after birth, which implicated a possible thromboembolic effect. We suggest that the mechanism of this unfavorable insult among survivors after sIUFD might not only be due to hypovolemic-ischemic damage, but also due to thromboembolism from demised twins. Furthermore, Wang et al. found that the long-term presence of D-dimer in the maternal serum may indicate a severe underlying thromboembolic complication in the surviving twin after an intrauterine death of a monochorionic twin [22].

The limitations of our study were the small number of patients. However, we did not only focus on neurological complications, but also on kidney injury and GI tract dysmotility.

Further studies for the optimal management strategies among survivors after sIUFD to improve the mortality and morbidity rates are recommended. This review study that explored detailed neonatal outcomes of survivors after sIUFD caused by TTTS may provide some information to evaluate the morbidity and mortality rates among surviving co-twins after sIUFD.

\section{Declarations}

\section{Acknowledgments}

We sincerely thank the patients and their family recruiting in this study and we are extremely thankful to the staff in Department of Pediatrics of the Cathay General Hospital.

\section{Authors' contributions}

Ya-Lan Lin, Yi-Li Hung, and Wu-Shiun Hsieh conceived and designed the study. Ya-Lan Lin analyzed the data. Ya-Lan Lin and Yi-Li Hung contributed to the writing of the manuscript. All authors agreed with the manuscript's results and conclusions, jointly made revisions and approved the final version of this editorial.

\section{Compliance with ethical standards}

Conflict of interest: the authors declare that they have no conflicts of interest relevant to this article or financial relationship with any organization.

Funding: there is no funding source. 
Ethical approval: this study was reviewed and approved by the Ethics Committee of the Cathay General Hospital Taipei, Taiwan (No. CGHP108010).

\section{References}

1. Kiely JL (1990) The epidemiology of perinatal mortality in multiple births. Bull NY Acad Med 66:618-37

2. Glinianaia SV, Pharoah POD, Wright C, Rankin JM (2002) Fetal or infant death in twin pregnancy: neurodevelopmental consequence for the survivor. Arch Dis Child Fetal Neonatal Ed 86:F9-15

3. van Heteren CF, Nijhuis JG, Semmekrot BA, et al (1998) Risk for surviving twin after fetal death of co-twin in twin-twin transfusion syndrome. Obstet Gynecol 92:215-19

4. Moore CM, McAdams AJ, Sutherland J (1969) Intrauterine disseminated intravascular coagulation: a syndrome of multiple pregnancy with a dead twin fetus. J Pediatr 74:523-28

5. Fusi L, McParland P, Fisk N, et al (1991) Acute twin-twin transfusion: a possible mechanism for brain-damaged survivors after intrauterine death of a monochorionic twin. Obstet Gynecol 78:517-20

6. Senat MV, Deprest J, Boulvain M, Paupe A, Winer N, Ville Y (2004) Endoscopic laser surgery versus serial amnioreduction for severe twin-totwin transfusion syndrome. N Engl J Med. 351:136-44

7. Ng PC, So KW, Fung KS, et al (2001) Randomised controlled study of oral erythromycin for treatment of gastrointestinal dysmotility in preterm infants. Arch Dis Child Fetal Neonatal Ed 84:F177-82

8. Selewski DT, Charlton JR, Jetton JG, et al (2015) Neonatal Acute Kidney Injury. Pediatrics 136:e463-73

9. Akkermans J, Peeters SHP, Klumper FJ, et al (2015) Twenty-five years of fetoscopic laser coagulation in twin-twin transfusion syndrome: A systematic review. Fetal Diagn Ther 38:241-53

10. E Quarello, J Stirnemann, M Nassar, B Nasr, J-P Bernard, F Leleu-Huard, Y Ville (2008) Outcome of anaemic monochorionicsingle survivors following early intrauterine rescue transfusion in cases of feto-fetal transfusion syndrome. BJOG115(5):595-601

11. Eglowstein M, D’Alton ME (1993) Single intrauterine demise in twin gestation. J Matern Fetal Med 2:272-5

12. Pharoah PO, Adi Y (2000) Consequences of in-utero death in a twin pregnancy. Lancet 355:1597-602

13. van Heteren CF, Nijhuis JG, Semmekrot BA, Mulders LG, van den Berg PP (1998) Risk for surviving twin after fetal death of co-twin in twintwin transfusion syndrome. Obstet Gynecol 92:215-19

14. Oberg KC1, Pestaner JP, Bielamowicz L, Hawkins EP (1999) Renal tubular dysgenesis in twin-twin transfusion syndrome. Pediatr Dev Pathol 2:25-32

15. Melhem NZ, Ledermann S, Rees L (2019) Chronic kidney disease following twin-to-twin transfusion syndrome-long-term outcomes. Pediatr Nephrol 34:883-888

16. Robel-Tillig E, Knüpfer M, Pulzer F, Vogtmann C (2004) Blood flow parameters of the superior mesenteric artery as an early predictor of intestinal dysmotility in preterm infants. Pediatr Radiol 34: 958-62

17. Reber KM, Nankervis CA, Nowicki PT (2002) Newborn intestinal circulation. Physiology and pathophysiology. Clin Perinatol 29:23-39

18. Bajoria R, Wee LY, Anwar S, Ward S (1999) Outcome of twin pregnancies complicated by single intrauterine death in relation to vascular anatomy of the monochorionic placenta.Hum Reprod14(8):2124-30

19. Saito K, Ohtsu Y, Amano K, Nishijima M (1999) Perinatal outcome and management of single fetal death in twin pregnancy: a case series and review. J Perinat Med 27:473-7

20. Johnson CD, Zhang J (2002) Survival of other fetuses after a fetal death in twin or triplet pregnancies. Obstet Gynecol 99:698-703

21. Prompeler HJ, Madjar H, Klosa W, du Bois A, Zahradnik HP, Schillinger H, et al (1994) Twin pregnancies with single fetal death. Acta Obstet Gynecol Scand 73:205-8

22. Wang KC, Yuan CC, Chao HT, Chang SP, Yang ML, Hung JH, et al (2000) Brain-damaged survivors after intrauterine death of a monochorionic twin. Zhonghua Yi Xue Za Zhi (Taipei) 63:673-8

23. Aslan H, Gul A, Cebeci A, Polat I, Ceylan Y (2004) The outcome of twin pregnancies complicated by single fetal death after 20 weeks of gestation. Twin Res 7:1-4

24. Axt R, Mink D, Hendrik J, Ertan K, von Blohn M, Schmidt W (1999) Maternal and neonatal outcome of twin pregnancies complicated by single fetal death. J Perinat Med 27:221-7

25. Petersen IR, Nyholm HC (1999) Multiple pregnancies with single intrauterine demise. Description of twenty-eight pregnancies. Acta Obstet Gynecol Scand 78:202-6区

26. So BH, Tamura M, Kamoshita S (1994) Liveborn twin with intrauterine death of one twin: report of two cases. Zhonghua Min Guo Xiao Er Ke Yi Xue Hui Za Zhi35(4):312-8

Page 5/6 
Tables

Table. Neonatal outcome of survivors after single-twin intrauterine fetal demise

\begin{tabular}{|c|c|c|c|c|c|c|c|c|c|c|}
\hline \multirow[t]{2}{*}{ Author } & $\begin{array}{l}\text { Reference } \\
\text { No. }\end{array}$ & $\begin{array}{l}\text { Year } \\
\text { of } \\
\text { Report }\end{array}$ & $\begin{array}{l}\text { Mean } \\
\text { interval } \\
\text { between } \\
\text { the } \\
\text { diagnosis } \\
\text { of fetal } \\
\text { death } \\
\text { and the } \\
\text { delivery }\end{array}$ & $\begin{array}{l}\text { Number } \\
\text { of } \\
\text { TTTS } \\
\text { cases }\end{array}$ & Anemia & $\begin{array}{l}\text { Neurological } \\
\text { damage }\end{array}$ & $\begin{array}{l}\text { Kidney } \\
\text { injury }\end{array}$ & $\begin{array}{l}\text { GI } \\
\text { dysmotility }\end{array}$ & $\begin{array}{l}\text { Mean } \\
\text { gestational } \\
\text { age at } \\
\text { delivery } \\
\text { (weeks) } \\
\text { (\% of } \\
\text { prematurity) }\end{array}$ & $\begin{array}{l}\text { Neonatal } \\
\text { mortality }\end{array}$ \\
\hline & & & (day) & & & & & & & \\
\hline Eglowstein & 11 & 1993 & $\begin{array}{l}\text { Not } \\
\text { stated }\end{array}$ & 7 & $\begin{array}{l}\text { Not } \\
\text { stated }\end{array}$ & $1(14.2 \%)$ & $\begin{array}{l}\text { Not } \\
\text { stated }\end{array}$ & Not stated & $30.6(100 \%)$ & 0 \\
\hline So & 26 & 1994 & $\begin{array}{l}\text { Not } \\
\text { stated }\end{array}$ & 2 & $\begin{array}{l}2 \\
(100 \%)\end{array}$ & $1(50 \%)$ & $\begin{array}{l}\text { Not } \\
\text { stated }\end{array}$ & Not stated & $27.5(100 \%)$ & 0 \\
\hline Prompeler & 21 & 1994 & $\begin{array}{l}\text { Not } \\
\text { stated }\end{array}$ & 4 & $\begin{array}{l}\text { Not } \\
\text { stated }\end{array}$ & Not stated & $\begin{array}{l}\text { Not } \\
\text { stated }\end{array}$ & Not stated & Not stated & $1(25 \%)$ \\
\hline $\begin{array}{l}\text { van } \\
\text { Heteren }\end{array}$ & 13 & 1998 & 14 & 11 & $\begin{array}{l}\text { Not } \\
\text { stated }\end{array}$ & $7(64 \%)$ & $1(9 \%)$ & Not stated & 32 (100\%) & $3(27.2 \%)$ \\
\hline Petersen & 25 & 1999 & $\begin{array}{l}\text { Not } \\
\text { stated }\end{array}$ & 3 & $\begin{array}{l}1 \\
(33.3 \%)\end{array}$ & Not stated & $\begin{array}{l}\text { Not } \\
\text { stated }\end{array}$ & Not stated & $30.3(100 \%)$ & 1(33.3\%) \\
\hline Saito & 19 & 1999 & 0 & 7 & $\begin{array}{l}\text { Not } \\
\text { stated }\end{array}$ & Not stated & $\begin{array}{l}\text { Not } \\
\text { stated }\end{array}$ & Not stated & $29.4(100 \%)$ & $4(57.1 \%)$ \\
\hline Axt & 24 & 1999 & 10 & 3 & $\begin{array}{l}\text { Not } \\
\text { stated }\end{array}$ & 1(33.3\%) & $\begin{array}{l}\text { Not } \\
\text { stated }\end{array}$ & Not stated & $32.3(100 \%)$ & 0 \\
\hline Bajoria & 18 & 1999 & $\begin{array}{l}\text { Not } \\
\text { stated }\end{array}$ & 26 & $\begin{array}{l}8 \\
(30.8 \%)\end{array}$ & Not stated & $\begin{array}{l}\text { Not } \\
\text { stated }\end{array}$ & Not stated & $26.6(100 \%)$ & $17(65.4 \%)$ \\
\hline Wang & 22 & 2000 & 22.7 & 9 & $\begin{array}{l}\text { Not } \\
\text { stated }\end{array}$ & $1(11.1 \%)$ & $\begin{array}{l}\text { Not } \\
\text { stated }\end{array}$ & Not stated & $33(100 \%)$ & 0 \\
\hline Aslan & 23 & 2004 & 11 & 8 & $\begin{array}{l}\text { Not } \\
\text { stated }\end{array}$ & Not stated & $\begin{array}{l}\text { Not } \\
\text { stated }\end{array}$ & Not stated & Not stated & $5(62.5 \%)$ \\
\hline Quarello & 10 & 2007 & $\begin{array}{l}\text { Not } \\
\text { stated }\end{array}$ & $39^{a}$ & $\begin{array}{l}9 \\
(23 \%)^{b}\end{array}$ & $4(10.2 \%)$ & $\begin{array}{l}\text { Not } \\
\text { stated }\end{array}$ & Not stated & Not stated & $\begin{array}{l}5^{c} \\
(12.8 \%)\end{array}$ \\
\hline Our cases & & 2020 & 5 & 5 & $4(80 \%)$ & $2(40 \%)$ & $3(60 \%)$ & $4(80 \%)$ & 30.8 (100\%) & $2(40 \%)$ \\
\hline Total & & & 10.5 & 124 & $\begin{array}{l}24 \\
(19.3 \%)\end{array}$ & 17(13.7\%) & $\begin{array}{l}4 \\
(3.2 \%)\end{array}$ & $4(3.2 \%)$ & $\begin{array}{l}29.5 \\
(58.8 \%)\end{array}$ & $38(30.6 \%)$ \\
\hline
\end{tabular}
a. Subtracted patients with photocoagulation lacer therapy
b. Nineteen cases had intrauterine transfusion
c. Termination of pregnancy: 3 , neonatal death: 2 